\title{
A computer database for falling snowflakes
}

\author{
Ken-IChiro Muramoto, KoHKi MatsuUra, \\ Department of Electrical and Computer Engineering, Faculty of Technology, Kanazawa University, Kanazawa 920, Japan \\ TOSHIO HARIMAYA, \\ Faculty of Science, Hokkaido University, Sapporo 060, Japan \\ TATSUO ENDOH \\ Institute of Low Temperature Science, Hokkaido University, Sapporo 060, Japan
}

\begin{abstract}
A computer-based measurement system for characteristics of snowfall is described. To measure the size and velocity of falling snowflakes quantitatively, images of snowflakes were input to an image processor and the primary data were analyzed in real time. In this process, maximum diameter in a horizontal plane and falling velocity were recorded in previously set intervals, then stored on a disk. Since a lot of data were obtained during a full winter season, data had to be processed to make up a database after an experiment. Using this database, the data of the distribution of size and velocity of snowflakes can be retrieved at anytime.

We observed snowflakes during winter months of 1986-92 in Sapporo and Toyama, which are located near the north east and middle of the Japan Sea coast respectively. The data indicate that the average size of snowflakes in Toyama was larger than that in Sapporo, while the number concentration of snowflakes in Sapporo was rather higher. The fall velocity tends to increase with increasing size of snowflakes, as observed in both areas.
\end{abstract}

\section{INTRODUGTION}

Measurement of the characteristics of snowflakes is important in the investigation of the growth process of snow particles (Locatelli and Hobbs, 1974; Reinking, 1979) and of radar measurement of snowfall (Carlson and Marshall, 1972; Collier and Larke, 1978; Boucher, 1985). In particular, data on the simultaneous and continuous observations of fall velocity, diameter and number concentration of snowflakes provide useful information. Furthermore, using these data it is possible to study the interannual variability of characteristics of snowfalls.

Various methods for measuring the size and velocity of falling snowflakes have been developed. For example, fall velocity has been measured by using a stopwatch (Magono and Nakamura, 1965; Jiusto and Bosworth, 1971), a camera (Langleben, 1954), light beams and photomultiplier tubes (Locatelli and Hobbs, 1974) and a stereoscopic camera system (Zikmunda and Vali, 1972). Suitable equipment, however, to automatically measure the physical parameters of snowflakes has not yet been developed.

In this paper, a new system is proposed which measures simultaneously the size and velocity of falling snowflakes, using a personal computer with an imageanalysis board. Characteristics of snowflakes in two areas were compared using this system.

\section{SYSTEM CONFIGURATION}

In order to protect falling snowflakes from wind and sunlight, a tower $2 \mathrm{~m}$ (in height) $\times 1.5 \mathrm{~m} \times 1.5 \mathrm{~m}$ was

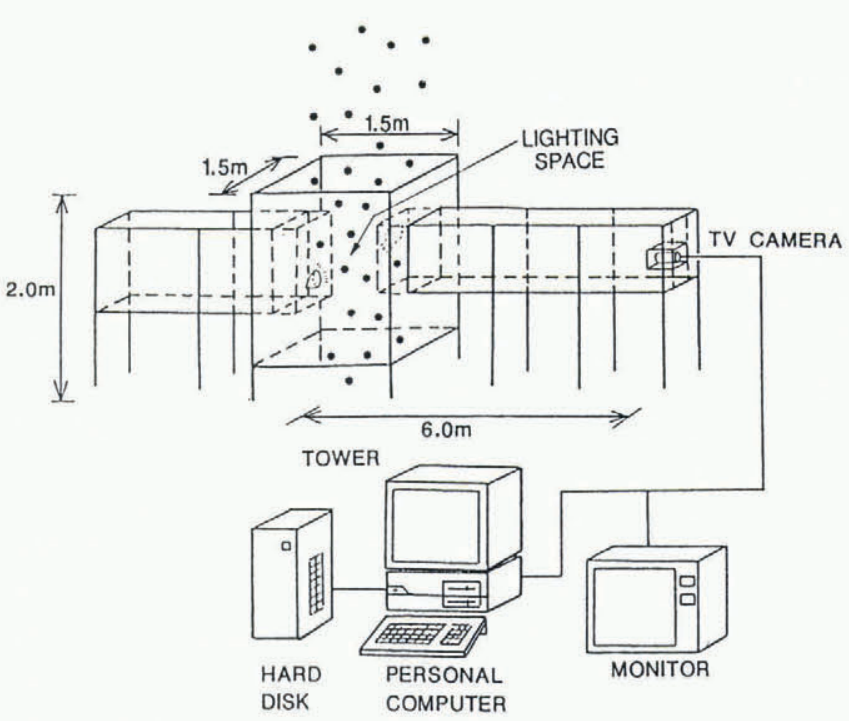

Fig. 1. System configuration for measurement of snowflakes. Snowflakes falling into the tower were illuminated by two halogen lamps and photographed ten times per min. 


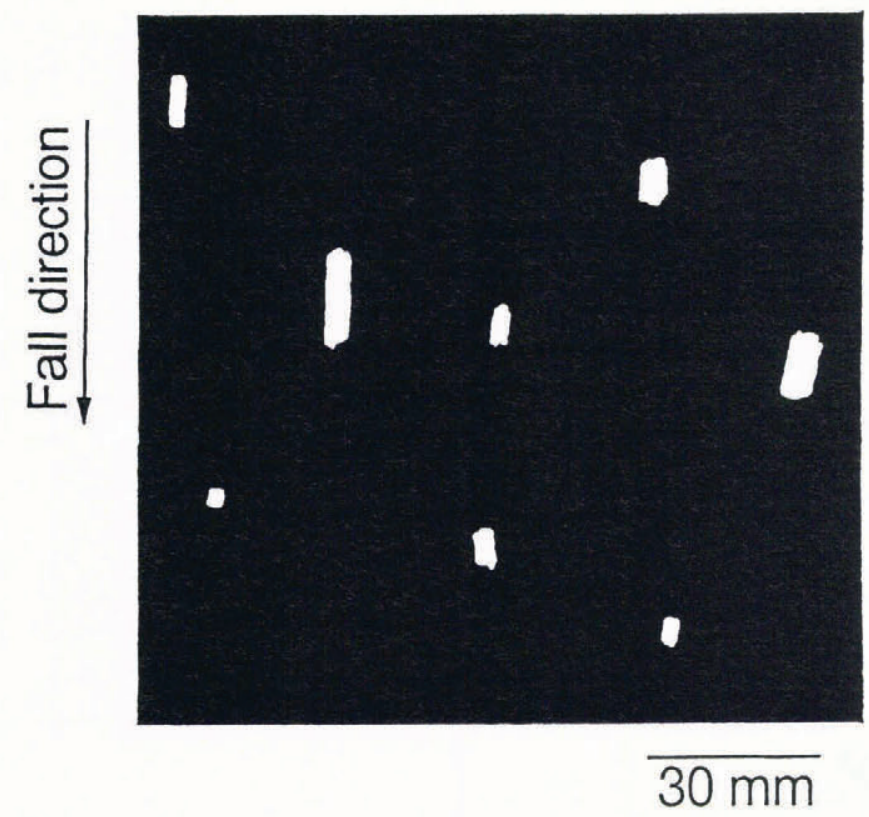

Fig. 2. Typical photograph of snowflake images. Since the shutter speed of camera was slow, images of snowflakes appeared as short streaks.

constructed, and a wind-breaker net $4 \mathrm{~m}$ (in height) $\times 3 \mathrm{~m} \times 3 \mathrm{~m}$ was installed around the tower to reduce the effect of the wind. Snowflakes fell vertically into the tower even during strong winds, ensuring accurate measurement of snowflake characteristics. The hardware diagram and measurements of the system are shown in Figure 1. The lighted space in the tower was illuminated from two directions by two halogen lamps. The photographing space inside the lighting space depended on the zooming range of a lens. To decrease the geometrical errors generated by the depth of field, the pictures of the falling snowflakes in the photographing space were taken by a zoom lens at a distance of $6 \mathrm{~m}$. Trajectories of snowflakes falling into the photographing space were photographed with a CCD TV camera ten times per min.

\section{MEASURING PROCESS}

A typical photograph of snowflake images is shown in Figure 2. Since the shutter speed of the TV camera was set at $1 / 60 \mathrm{~s}$, the photographed images of snowflakes appeared as short streaks. The images were converted into digital form with an image-analysis board installed on a personal computer. Digitized images consisted of a $256 \times 256$ pixel array, each pixel having a designated gray value ranging from 0 to 255 .

Photographed pictures were composed of two kinds of regions that occupy different gray-level ranges, and all parts of the snowflake images were lighter than the background image. Therefore the pixels whose gray levels were lighter than the background were considered as snowflakes. The pictures of snowflakes could thus be segmented. Figure 3A shows the binary image of a snowflake consisting of pixels. The snowflake is depicted by white round pixels.

\section{Extraction of snowflake}

A snowflake is found by scanning on each line from the left end towards the right side, from the top to bottom line as shown in Figure 3A. When the topmost pixel of a snowflake (S) is detected, the horizontal extent of the snowflake in the same line is computed. In a similar way, pixels of the bottom line are computed. This process is continued as far as pixels of the same snowflake are detected. When a pixel of the snowflake is not found under the line, the search for the snowflake is finished. In this way, the position of both the ends in each row is computed. The same procedure is repeated until detection of all the snowflakes is finished. This method is faster than a continuous search for all pixels in a regular sequence. Since the depth of the photographing space is limited to $20 \mathrm{~cm}$, it seldom happens that snowflakes overlap each other throughout the observations.

\section{Size of snowflakes}

Since the shutter speed is set at $1 / 60 \mathrm{~s}$, the observed images of snowflakes falling into the tower are seen as streaks which are longer than the actual snowflakes. Therefore, the maximum width (XW) as shown in Figure $3 \mathrm{~A}$ is considered to be the diameter of the snowflakes.

\section{Fall velocity of snowflakes}

Since each falling snowflake produces a short streak during $1 / 60 \mathrm{~s}$, its velocity is calculated from its vertical length (YW). If the assumption is made that each
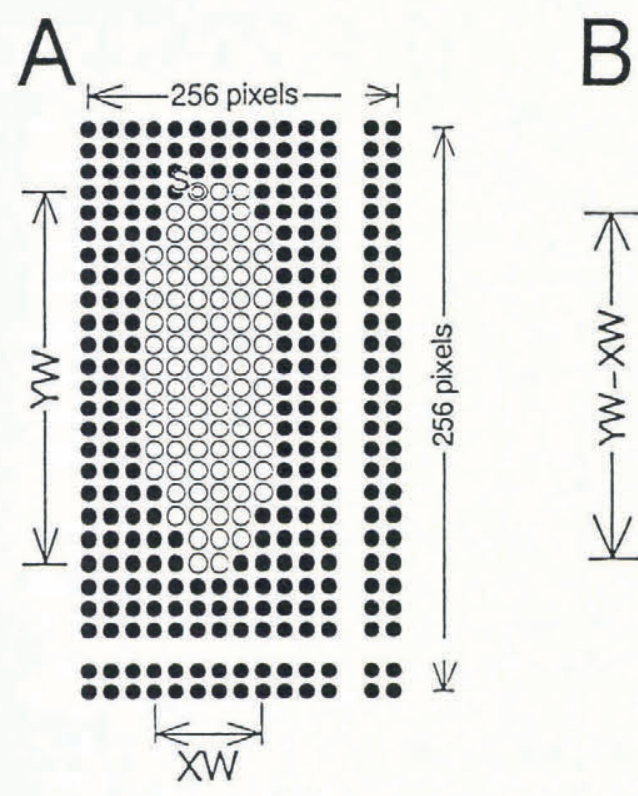

Fig. 3. A, binary image of snowflake consisting of pixels. Calculation is started from the topmost pixel (S) of snowflakes. The maximum distance between the both ends in each row $(X W)$ and maximum vertical length $(r W)$ are computed. Size of pixels depends on the length of photographing space shown in Table 1. B, assuming that each snowflake is spherical and its diameter is $(X W)$, snowflakes fall $(Y W-X W)$ in $1 / 60$ s. 
snowflake is spherical, and that diameter (XW) is as shown in Figure 3B, its falling distance is ( $\mathrm{YW}-\mathrm{XW}$ ) for $1 / 60 \mathrm{~s}$. Using this method, it is possible to quickly compute the falling velocity of all snowflakes.

\section{Number concentration of snowflakes}

The number of snowflakes is calculated by counting the number of streaks in the photographing space. The number concentration per unit space is computed from the observed data on the number of snowflakes in the photographing space.

\section{DATABASE}

\section{Data processing}

The diameter, the fall velocity and the number of snowflakes are computed from binary images of observed snowflakes, and recorded on a disk every $6 \mathrm{~s}$. After an observation, these data are accumulated in a $60 \mathrm{~s}$ interval. To normalize the output file, snowflakes are divided into 20 groups according to their diameters. The minimum diameter that can be detected depends on the size of photographing space. The maximum diameter is determined by 20 times the length of the minimum one. Table 1 lists the relationship between the length of photographing space and the minimum and maximum diameters that can be detected. To reduce the calculation time on retrieving the mean and standard deviation of fall velocity, data for fall velocity for each diameter are also stored.

\section{Data retrieval and display on a graphic terminal}

Data on the characteristics of falling snowflakes are accessed in an arbitrary time period from the database.
Table 1. Relationship between the length of photographing space and the minimum and maximum diameter of the snowflakes

\section{Diameter}

$\begin{array}{ll}\text { Min. } & \text { Max. } \\ (\mathrm{mm}) & (\mathrm{mm})\end{array}$

$(\mathrm{mm})$

$(\mathrm{mm})$

$(\mathrm{mm})$

The retrieved data are displayed on a graphical monitor (resolution, 640 horizontal pixels $\times 400$ vertical lines). For the histogram of time series data, 480 horizontal pixels are used in this system, enabling $8 \mathrm{~h}$ data to be shown per line. To show a histogram which is longer than $8 \mathrm{~h}$, retrieved data must be averaged by suitable time intervals.

\section{RESULTS}

\section{Observations}

Observations were carried out in Sapporo and Toyama, which are located near the northeast and middle of the Japan Sea coast respectively, from January to March, 1986-92. In general, the temperature is lower in Sapporo than in Toyama.
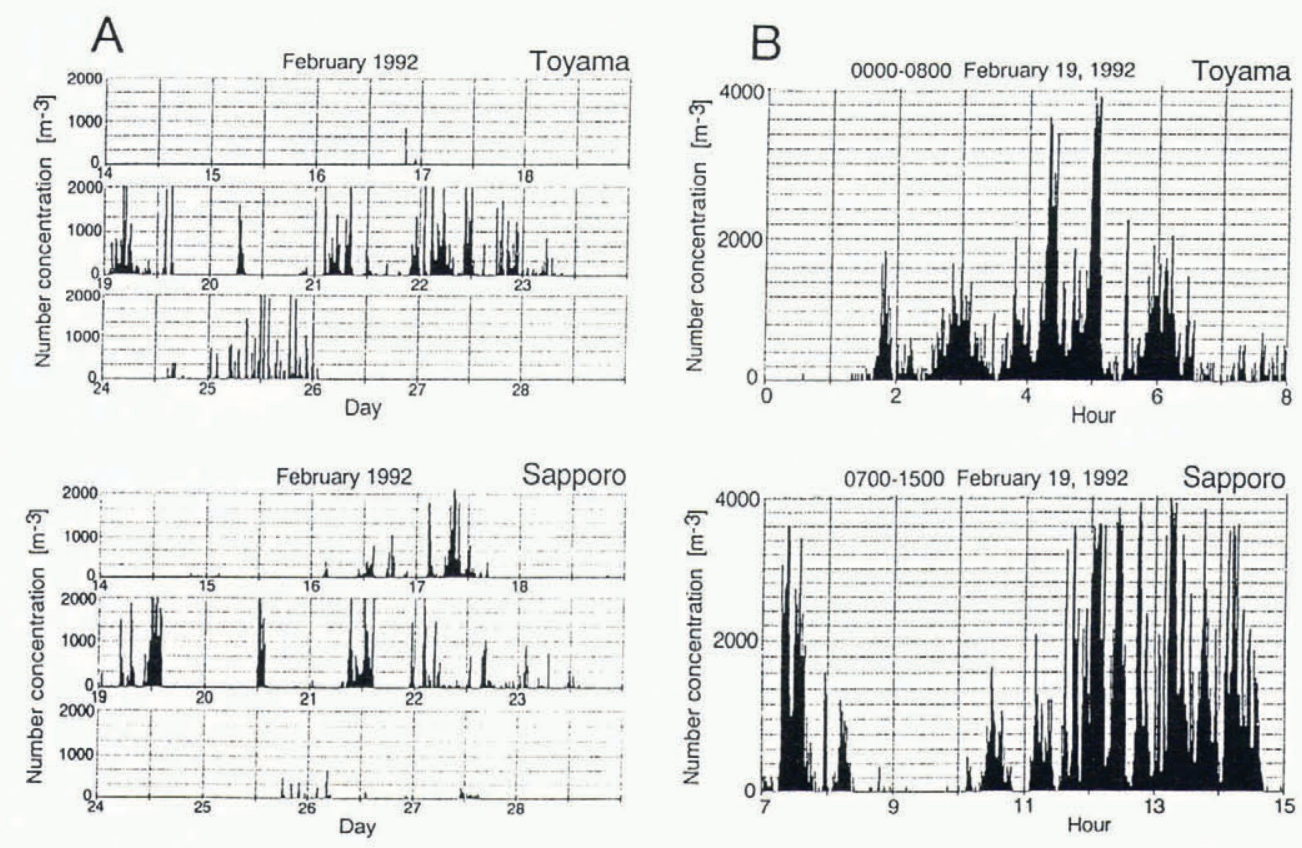

Fig. 4. Histograms of number concentration for $A(15 d)$ and $B(8 h)$ in Toyama and Sapporo. Data were averaged in 15 min intervals in $A$. 
Toyama
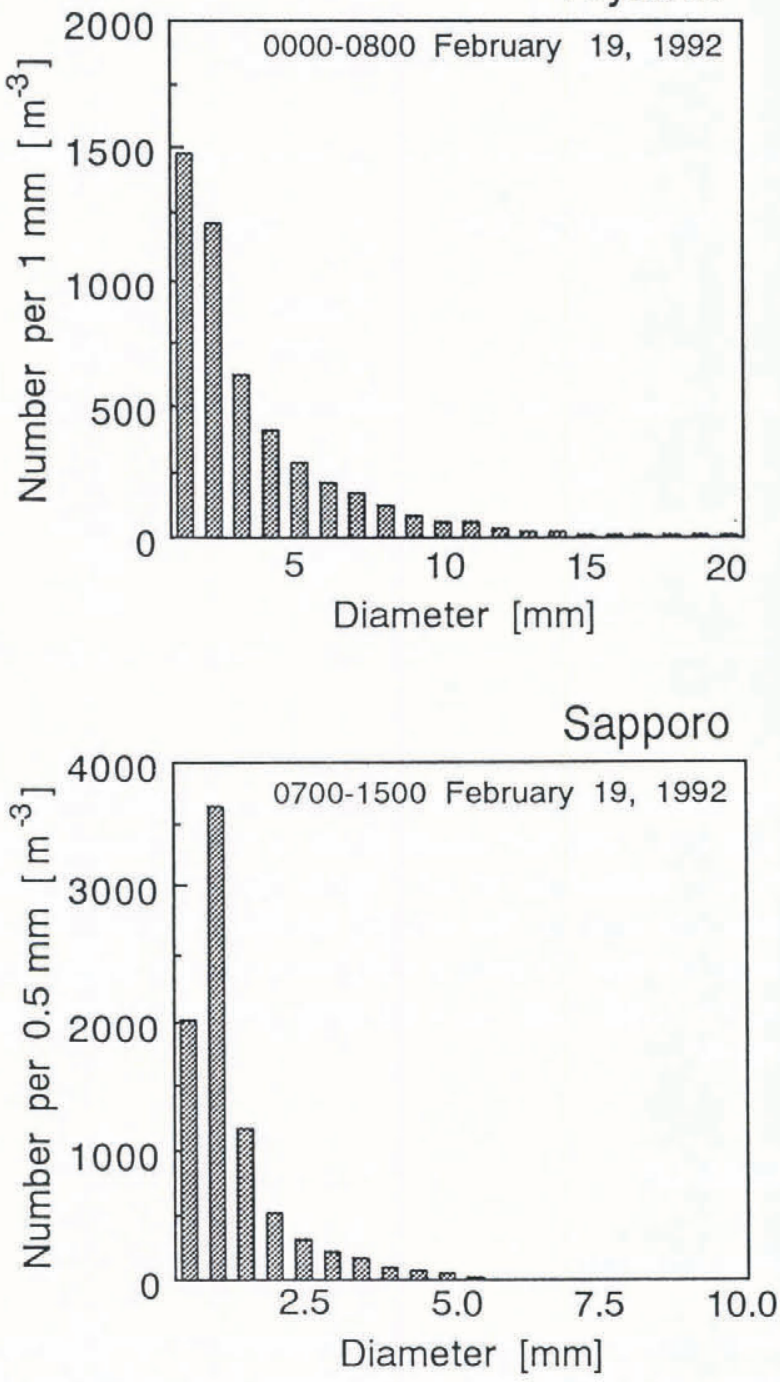

Fig. 5. Frequency distributions of snowflakes during $8 h$. A, Toyama; B, Sapporo.

\section{Number concentration}

The number concentrations in Toyama and Sapporo on 14-28 February 1992 are shown in Figure 4. The number concentration in Sapporo was higher than that in Toyama.

\section{Diameter of snowflakes}

Frequency distributions of snowflakes are shown in Figure 5. Figure 6 shows the time series of the mean diameter of all observed snowflakes. The mean diameter of snowflakes was about $3.0 \mathrm{~mm}$ in Toyama and about $1.5 \mathrm{~mm}$ in Sapporo. The temperature of this period was $0.5^{\circ}$ to $0.9^{\circ} \mathrm{C}\left(0.65^{\circ} \pm 0.13^{\circ} \mathrm{C}\right)$ in Toyama and $-6.9^{\circ}$ to $-4.1^{\circ} \mathrm{C}\left(-5.41^{\circ} \pm 0.89^{\circ} \mathrm{C}\right)$ in Sapporo. Differences between Toyama and Sapporo for frequency distribution and diameter were probably due to the temperature.

\section{Fall velocity}

The mean and standard deviation of fall velocity for each measured diameter were retrieved from the database. Since these data were stored beforehand, the calculation

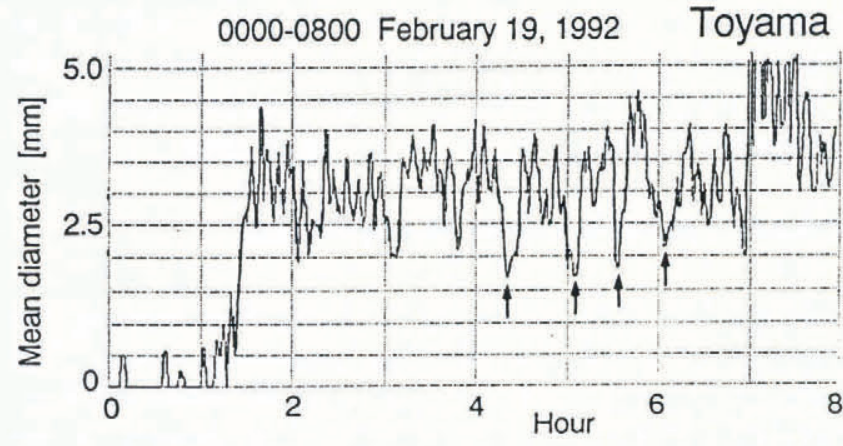

0700-1500 February 19, 1992

Sapporo

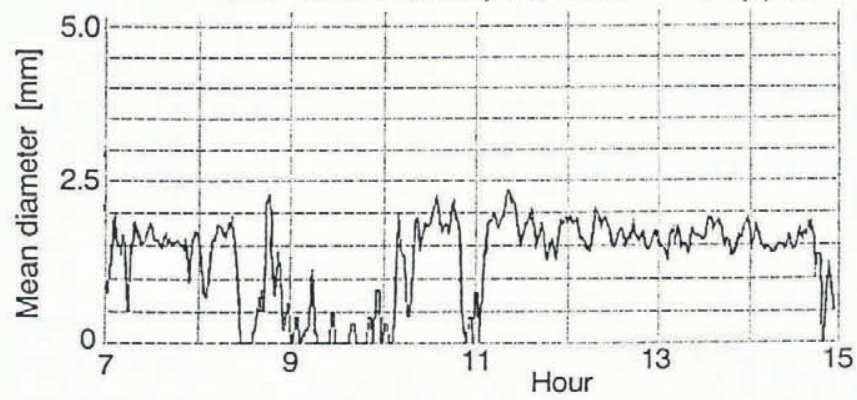

Fig. 6. Time series of the mean diameter of all observed snowflakes. Arrows indicate the times when the number concentration was very large, as shown in Figure 5B.

time was reduced. Figure 7 shows fall velocity versus the diameter of the snowflakes. These data indicate that the velocity increases slowly with increasing diameter, results that agree with previous reports (Langleben, 1954; Magono and Nakamura, 1965; Jiusto and Bosworth, 1971; Locatelli and Hobbs, 1974). Figure 8 shows the
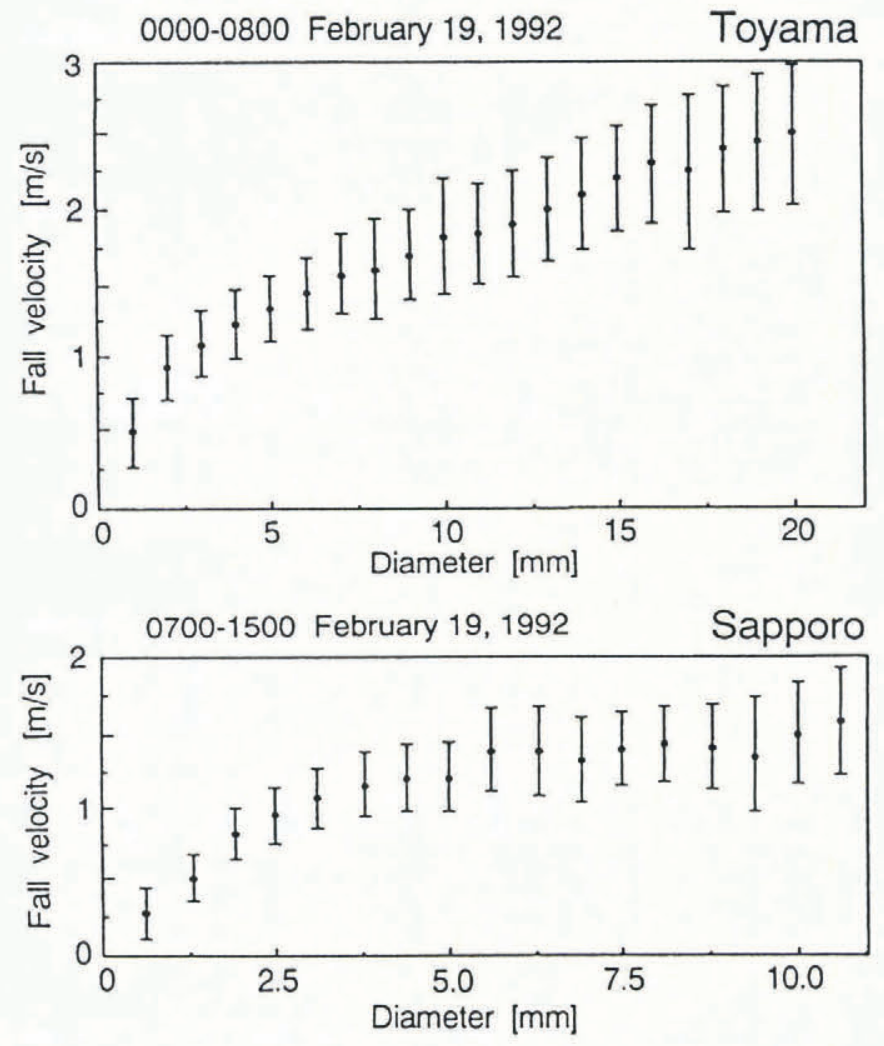

Fig. 7. Fall velocity versus diameter of snowflakes. 

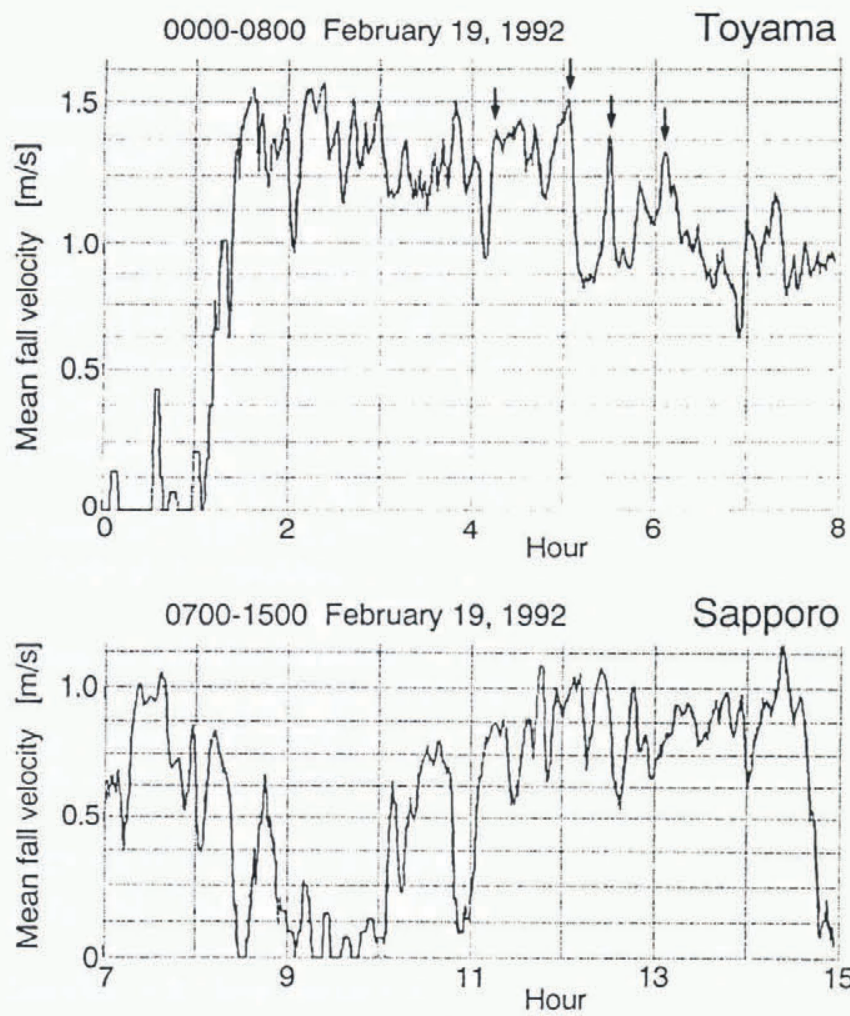

Fig. 8. Time series of the mean fall velocity of all observed snowflakes. Arrows as in Figure 6.

time series of mean fall velocity of all observed snowflakes. The mean fall velocity was $0.6-1.5 \mathrm{~m} \mathrm{~s}^{-1}$ in Toyama and $0.5-1.0 \mathrm{~m} \mathrm{~s}^{-1}$ in Sapporo. The mean diameter of snowflakes in Toyama was larger than that in Sapporo (Fig. 6), and velocity increased with increasing diameter (Fig. 7). Therefore, it was reasonable to assume that the mean velocity in Toyama was greater than that in Sapporo.

From the same period, data on the number concentration (Fig. 4B), the mean diameter (Fig. 6) and the mean fall velocity (Fig. 8) allow these relationships to be examined. Generally, velocity increased with increasing diameter as mentioned above. There were some cases, however, where the velocity increased with decreasing diameter at a time when the number concentration was very large, as shown by arrows in Figures 6 and 8 . When the number concentration is large, snowflake collision during fall causes large aggregates (Passarelli, 1978; Kenneth and Passarelli, 1982).

\section{Falling period}

Figure 9 is the time series of the daily period of snowfall for February for three years; there are some patterns in this data. Similarly, Figure 10 shows the monthly data for February and March during the period 1986-92; it shows that there was little snowfall in 1989 and 1990. These data will be useful for long-term records of interannual time-scale phenomena in the atmosphere.

\section{CONGLUSION}

A new measuring system has been developed which can automatically and simultaneously measure the size and velocity of falling snowflakes over a long period. The images of snowflakes taken by a CCD TV camera were fed into an image-analysis board installed on a computer to extract the useful features of snowfall. In these processes, information on each image of snowflakes was selected with two parameters: width and vertical length. Long-term observations were realized by this method.

Since a lot of data were obtained, a database was made that could retrieve the characteristics of snowfall easily. In this database, retrieval time was reduced by calculating the standard deviations of fall velocities beforehand.

Using this system, relationships between the number concentration, the diameter, the fall velocity and the falling period were analyzed. It would be useful to measure other parameters of snowflakes simultaneously. For example, it becomes possible to compare the physical
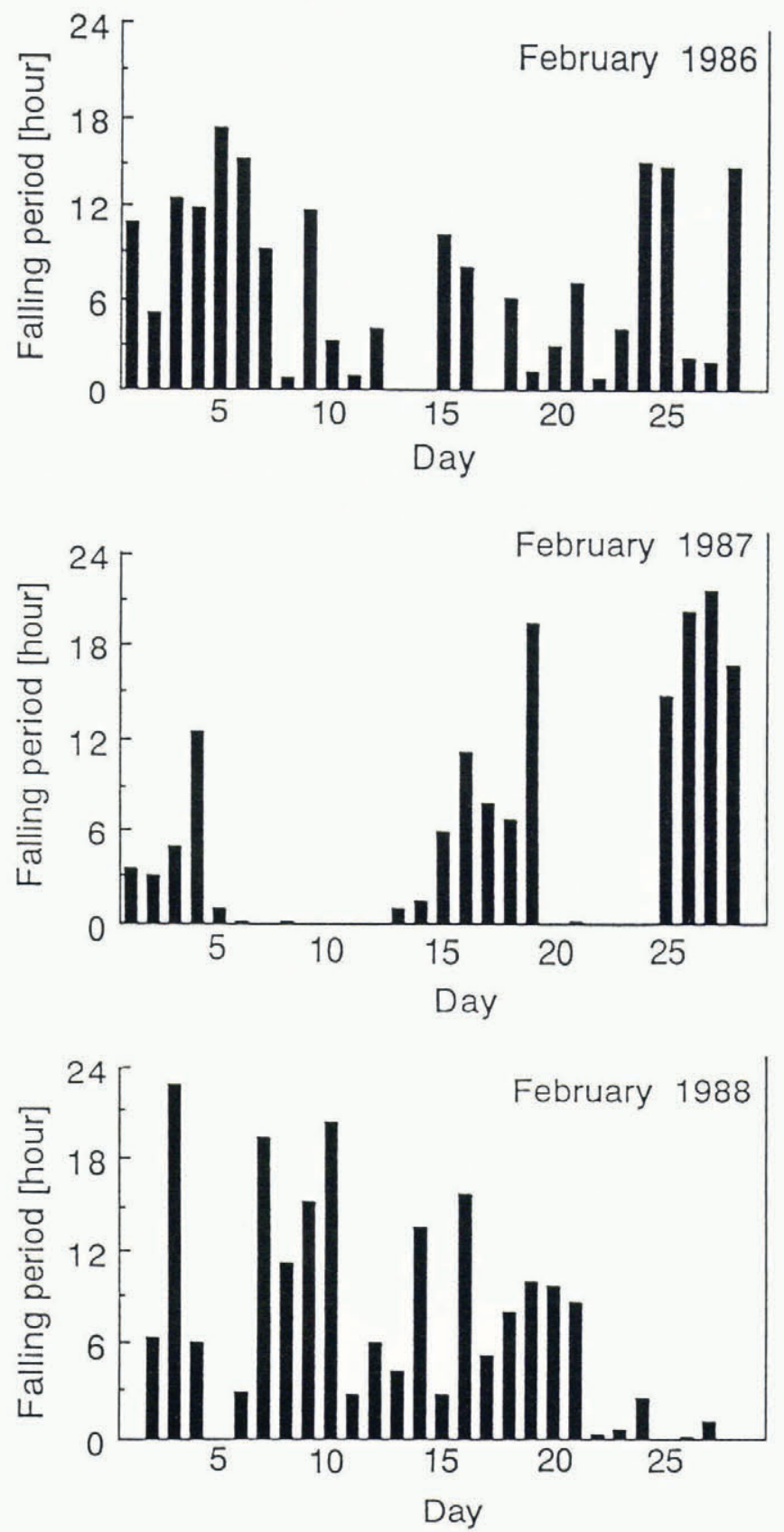

Fig. 9. Time series of the daily period of snowfall for February for three years. 


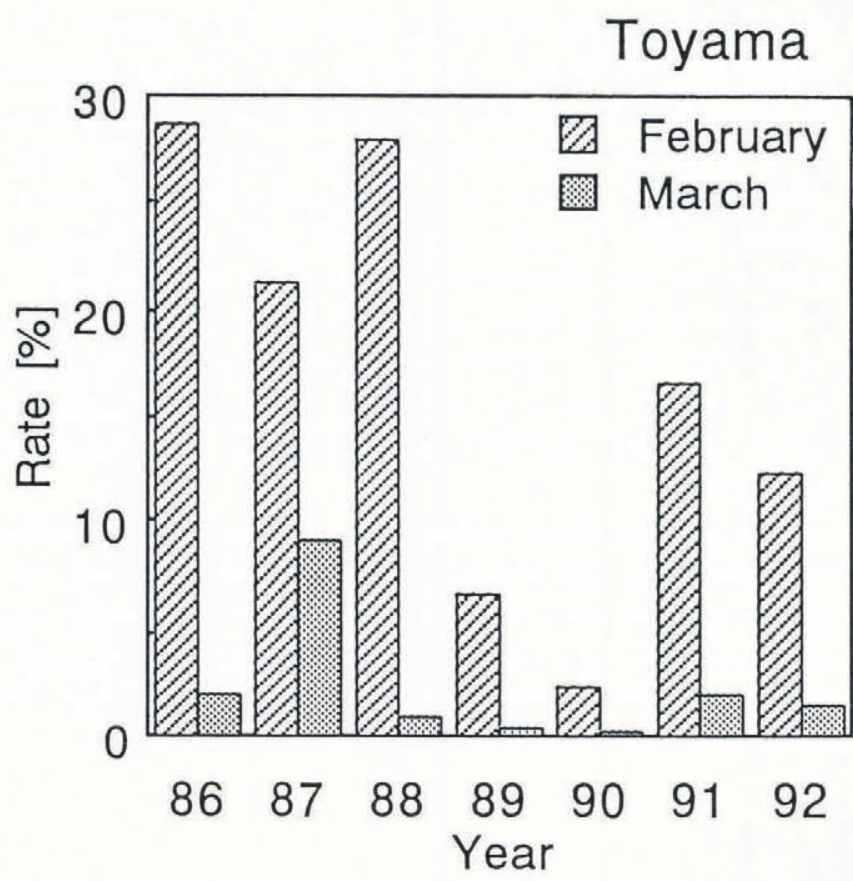

Fig. 10. Monthly rate of snowfall period for 1986-92.

parameters of snowflakes at the ground and, using a radar, their structure in the cloud, with data of snow quality obtained by using a snow-weight meter.

\section{ACKNOWLEDGEMENTS}

The authors thank T. Suzuki for development of software. This research was partly supported by the Betsukawa Foundation.

\section{REFERENCES}

Boucher, R.J. and J. C. Wieler. 1985. Radar determination of snowfall rate and accumulation. F. Climate Appl. Meteorol., 24(1), 68-73.

Carlson, P.E. and J. S. Marshall. 1972. Measurement of snowfall by radar. F. Appl. Meteorol., 11(3), 494-500.

Collier, C. G. and P. R. Larke. 1978. A case study of the measurement of snowfall by radar: an assessment of accuracy. Q F. R. Meteorol. Soc., 104(441), 615-621.

Jiusto, J.E. and G.E. Bosworth. 1971. Fall velocity of snowflakes. J. Appl. Meteorol., 10(6), 1352-1354.

Kenneth, K. L. and R. E. Passarelli, Jr. 1982. The growth of snow in winter storms; an airborne observational study. F. Atmos. Sci., 39, 697-706.

Langleben, M.P. 1954. The terminal velocity of snowflakes. Q. F. R. Meteorol. Soc., 80(344), 174-181.

Locatelli, J.D. and P.V. Hobbs. 1974. Fall speeds and masses of solid precipitation particles. 7. Geophys. Res., 79(15), 2185-2197.

Magono, C. and T. Nakamura. 1965. Aerodynamic studies of falling snowflakes. F. Meteorol. Soc. Jpn., 43(3), 139-147.

Passarelli, R. E., Jr. 1978. Theoretical and observational study of snow-size spectra and snowflake aggregation efficiencies. F. Atmos. Sci., 35(5), 882-889.

Reinking, R. F. 1979. The onset and early growth of snow crystals by accretion of droplets. F. Atmos. Sci., 36(5), 870-881.

Zikmunda, J. and B. Vali. 1972. Fall patterns and fall velocities of rimed ice crystals. F. Atmos. Sci., 29(7), 1334-1347.

The accuracy of references in the text and in this list is the responsibility of the authors, to whom queries should be addressed. 